\title{
Free-flight force measurement technique in shock tunnel
}

\author{
TANNO Hideyuki ${ }^{*}$, KOMURO Tomoyuki $^{\dagger}$, SATO Kazuo $^{\dagger}$, ITOH Katsuhiro ${ }^{\ddagger}$, TAKAHASHI Masahiro ${ }^{\dagger}$, \\ Japan Aerospace Exploration Agency, Kakuda Space Center, \\ Kakuda Miyagi 981-1525 JAPAN \\ FUJITA Kazuhisa ${ }^{\S}$ \\ Japan Aerospace Exploration Agency, Chofu Aerospace Center, \\ Chofu Tokyo 182-8522 JAPAN \\ Stuart Laurence ${ }^{\Uparrow}$ and Klaus Hannemann $*$ \\ German Aerospace Center, Institute of Aerodynamics and Flow Technology Spacecrafts \\ Bunsenstr. Göttingen 37073 GERMANY
}

\begin{abstract}
A novel force measurement technique has been developed at the impulsive facility HIEST, in which the test model is completely non-restrained for the duration of the test, so it experiences completely free-flight conditions for a period on the order of milliseconds. This technique was demonstrated with a three-component aerodynamic force measurement with a blunted cone of total length $318 \mathrm{~mm}$ and a total mass of $22 \mathrm{~kg}$ in hypervelocity test flow. A miniature modelonboard data-logger, which was a key technology for this technique, was also developed in order to store the measured data. The data-logger was designed to be small enough to be instrumented in test models, with an overall size of $100 \mathrm{~mm} \times 100 \mathrm{~mm} \times 70 \mathrm{~mm}$, including batteries. Since the logger was designed to measure force and pressure, it includes six piezoelectric amplifiers and four piezoresistive amplifiers, as well as high-speed analogue-digital converters, which digitize the measured data with 16-bit resolution. The logger's sampling rate and sample size are 500 kHz and $400 \mathrm{~ms}$, respectively. For the autonomous operation, the logger waits for a trigger signal (accelerometer output) and then starts to take measurements with arbitrary adjustable trigger threshold level and pre-trigger delay time. Measured data is stored to static memory for transfer to a PC via a USB interface after a wind tunnel test. To demonstrate the entire measurement system, wind tunnel experiments were conducted in HIEST. In the present wind tunnel test campaign, records of pressure, axial force, nominal force and pitching moment were obtained under conditions of $\mathrm{H}_{0}=4 \mathrm{MJ} / \mathrm{kg}, \mathrm{P}_{0}=14 \mathrm{MPa}$. This demonstrated that the system worked correctly in the short test duration and harsh conditions typical of HIEST. Use of this data-logger allows the elimination of a large-diameter sting, ending concerns about the sting's interference with the base flow of the model, which could cause serious errors in measurement in wind tunnel tests.
\end{abstract}

\footnotetext{
*Senior Researcher, Space Transportation Propulsion Research and Development Center, Space transportation mission directorates, tanno.hideyuki@jaxa.jp, Senior member AIAA

${ }^{\dagger}$ Senior Researcher, Space Transportation Propulsion Research and Development Center, Space transportation mission directorates

${ }_{\ddagger}^{\ddagger}$ Deputy Manager, Space Transportation Propulsion Research and Development Center, Space transportation mission directorates, Senior member AIAA

${ }^{\S}$ Senior Researcher, Aerospace research and development directorates, Senior member AIAA

"Research Scientist, Spacecraft Department, DLR Gottingen, Stuart.Laurence@dlr.de, Member AIAA

※Head Spacecraft Department, DLR Gottingen, Klaus.Hannemann@dlr.de, Member AIAA
} 


\section{Introduction}

The interference of the sting with a model base flow is a wellknown technical issue in wind tunnel force measurement, and considered a major source of error. Since its dynamic pressure is higher than that of conventional wind tunnels, the free-piston shock tunnel HIEST ${ }^{1}$ (Fig.1) requires stiffer and hence largerdiameter stings. Base flow interference in HIEST is consequently more significant than in conventional wind tunnels. To solve the sting problem, we are trying to develop a new measurement technique with a no-sting model-support system. In this technique, the model will be released and fall from a model holder installed on the ceiling, in synchrony with the arrival of the test flow. During their entire passage through the test flow, test models will be completely free from any support system in what we call the 'free-fall force measurement technique' as shown in Fig.2. After termination of the test flow, the model will be caught by a soft-landing system placed on the floor so that the model and instruments can be reused. As part of developing the technique, we have been conducting basic research on applicable instrumentation. As a first step, we developed a force measurement technique that uses weakly restrained test models ${ }^{2}$ with miniature accelerometers installed to measure aerodynamic forces directly. In this technique, models are suspended by two thin wires, leaving the model free to move. We could thus use a small-diameter sting instead of a large one However, that small diameter sting at the aft of the model was still required for the signal cables from the model. As a second step, we developed a miniature data-logger ${ }^{3}$ that can be mounted onboard a model and that can operate autonomously and completely without a sting. This data-logger has the potential to make test models completely free from support systems involving stings or support wires. As an added benefit, the signals will be improved by the elimination of the electrical noise sometimes picked up by the long signal cables connecting the test models with amplifier stations outside the HIEST test section (HIEST usually requires $7 \mathrm{~m}$ cables). However, there is still aerodynamic interference from wires to suspend the model.

This report describes the final step of the development of the 'free-fall force measurement technique'. To remove suspension wires, we developed a magnetic model hold-and-release system and also a model catcher system to allow soft landings. In this paper, we describe the details and basic characteristics of the model hold-and-release system and the catcher. A force-measurement wind tunnel test campaign was carried out in HIEST, integrating all the measurement systems under hypersonic high-enthalpy flow conditions. The three-component aerodynamic force on a blunted cone model was measured with the present 'free-fall force measurement technique'. The miniature datalogger onboard in the model successfully measured the six-channel acceleration and was recovered without damage after the shot.

\section{Force measurements in short test duration}

Aerodynamic force measurements in shock tunnels present technical difficulties due to their short test durations and high-stagnation pressures and enthalpies compared with conventional wind tunnels. Because no facilities are yet available to reproduce the high stagnation conditions of reentry, aerodynamic testing in shock tunnels is vitally 
important to produce benchmarks for the validation of numerical codes describing hypervelocity flows. Hence, a very large number of studies have been directed at this problem ${ }^{4}$ since the $1960 \mathrm{~s}$. The semi-free-flight technique

Table.1 Specifications of the miniature data-logger.

\begin{tabular}{cl}
\hline Sensor type & piezoelectric ICP type (PCB ) and piezoresistive (Kulite) \\
Number of channels & 10 (six channels for piezoelectric and four channels for piezoresistive) \\
Input & $-10 \mathrm{~V}$ to $10 \mathrm{~V}$ \\
Resolution & $16 \mathrm{bit}$ \\
Sampling rate & $500 \mathrm{kHz}$ (for each channel) \\
Duration & $400 \mathrm{~ms}$ \\
Pre-trigger & Adjustable from -400 ms to 0 ms with onboard micro switch \\
Trigger arm system & IR photo-switch. (with LED indicator) \\
Size & 50 mm x 70 mm x 40 mm \\
Battery life & 2 hours \\
Interface & USB
\end{tabular}

(weakly restrained model support method) is one popular method for force measurement in shock tunnels. In the past few decades, this method has been modified by several researchers for several applications ${ }^{5-7}$. The present authors also have been doing basic studies using this 'semi-free-flight' technique for force measurement in HIEST. Although we succeeded in measuring three component aerodynamic forces with a time resolution of $330 \mu$ s, we found there were significant differences between the predictions of numerical codes and the measured values ${ }^{8}$. While the reasons for the differences are not yet clear, the sting at the aft end of the model is a concern, as it may interfere with the base flow. We planned to use a miniature data-logger inside the model, to eliminate the need for a sting on aerodynamic models.

The data-logger was originally designed to be mounted inside aerodynamic test models in the HIEST shock tunnel. The HIEST is a free-piston type high-enthalpy shock tunnel, measuring $87 \mathrm{~m}$ and 400 metric tons. HIEST can produce stagnation pressures up to $150 \mathrm{MPa}$ and stagnation temperatures up to $10000 \mathrm{~K}$. Although the tunnel can produce longer test durations than any other shock tunnel facility, its test time is still on the order of milliseconds. The test time depends on the operating conditions. For example, we can get a test time of $7 \mathrm{~ms}$ or longer at $\mathrm{H}_{0}=4$

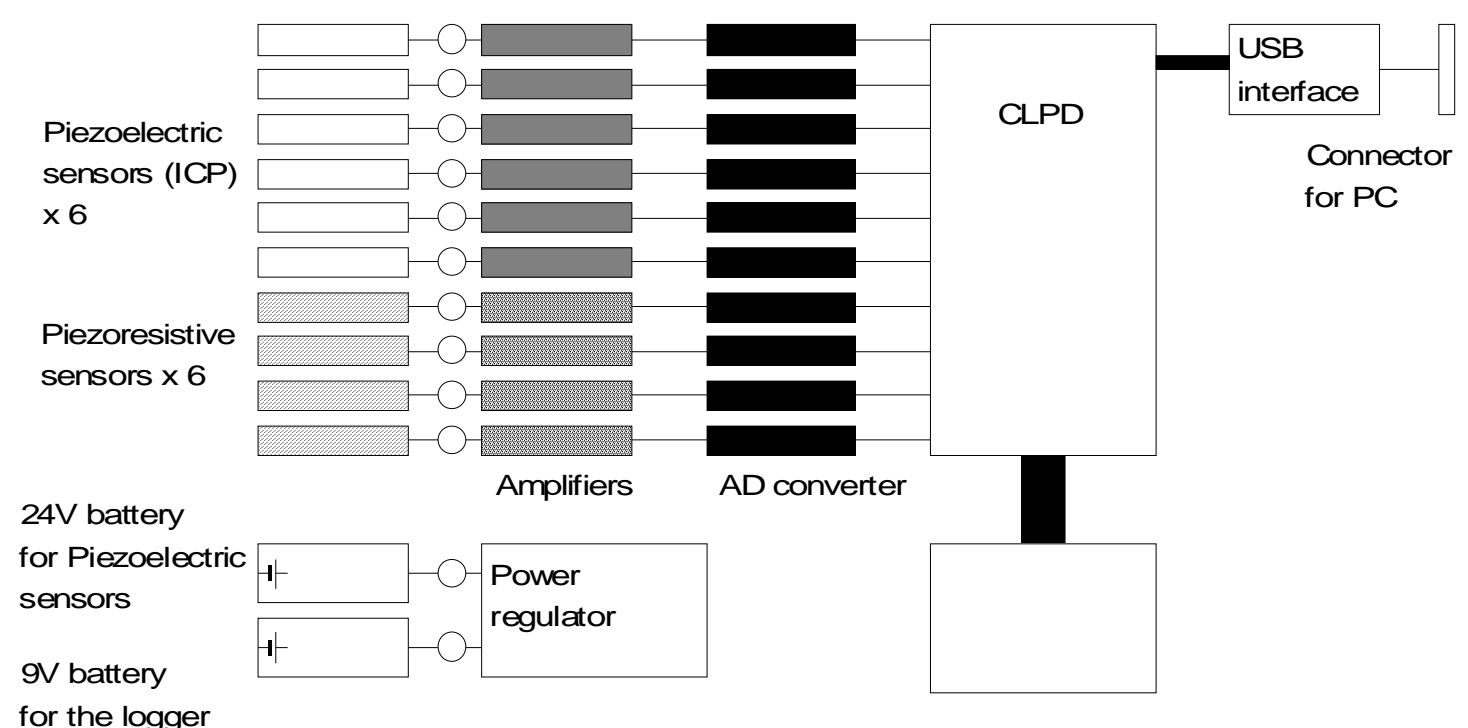

Figure.3 Block diagram of the onboard data-logger.

3

American Institute of Aeronautics and Astronautics 


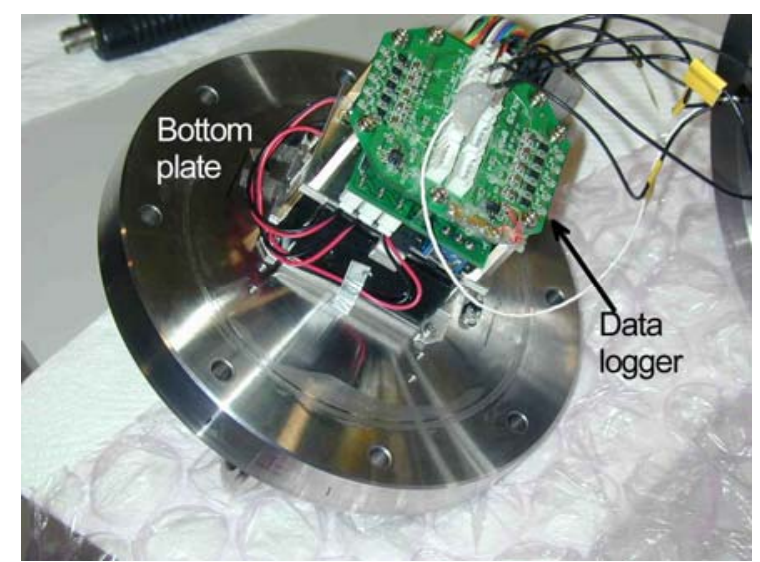

Figure.4 The miniature data-logger mounted on the bottom plate of the blunted-cone wind tunnel test model. The logger has 6-channel piezoelectric amplifiers and 4-channel piezoresistive amplifiers.

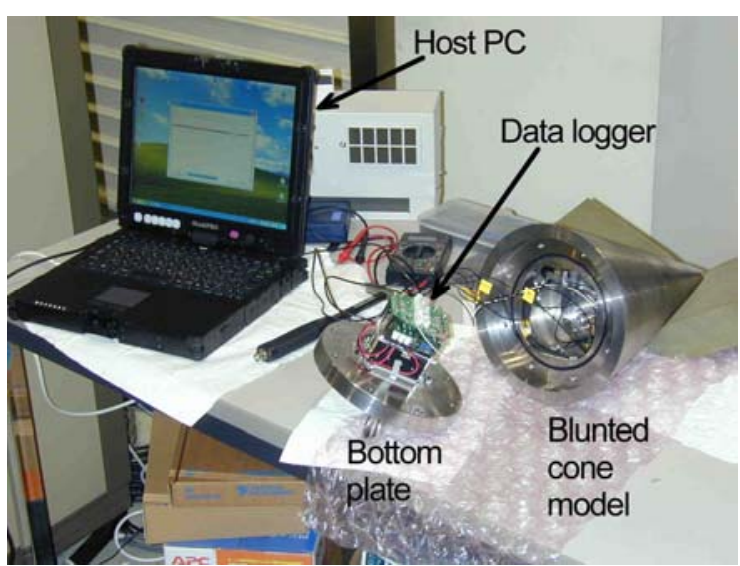

Figure.5 Measured data was transferred to the host $P C$ via a USB interface

$\mathrm{MJ} / \mathrm{kg}$ and $\mathrm{P}_{0}=14 \mathrm{MPa}$, and $5 \mathrm{~ms}$ at $\mathrm{H}_{0}=7 \mathrm{MJ} / \mathrm{kg}$ and $\mathrm{P}_{0}=30 \mathrm{MPa}$. With low-pressure shots up to $\mathrm{P}_{0}=30 \mathrm{MPa}$, we can operate HIEST twice a day. Conical and contoured nozzles are available for HIEST. In the present study, a contoured nozzle was used. With a contoured nozzle, we can get the diameter of the test core flow to approximately $300 \mathrm{~mm}$ at $\mathrm{H}_{0}=4 \mathrm{MJ} / \mathrm{kg}$ and $\mathrm{P}_{0}=14 \mathrm{MPa}$.

\section{Free-flight in shock tunnel HIEST}

The procedure of the present test technique is shown as the follows. At the initial status of the wind tunnel test, a test model (Blunted cone in the figure) was suspended from electromagnets fixed on the test-section ceiling. The model was released when a triggering signal arrived from the tunnel start signal. The model then fell so that it met the hypersonic test flow just as it arrived in the test section. Test duration of HIEST is order of ms, while the model falls few centi-meter during the test because of the falling speed of the model will be order of few meter. Hence will remain the test-core flow during the test period. Finally, model is going to make a soft landing on a model catcher with four hydraulic shock absorbers. With the soft landing recovery system, model will be reused without nodamages.

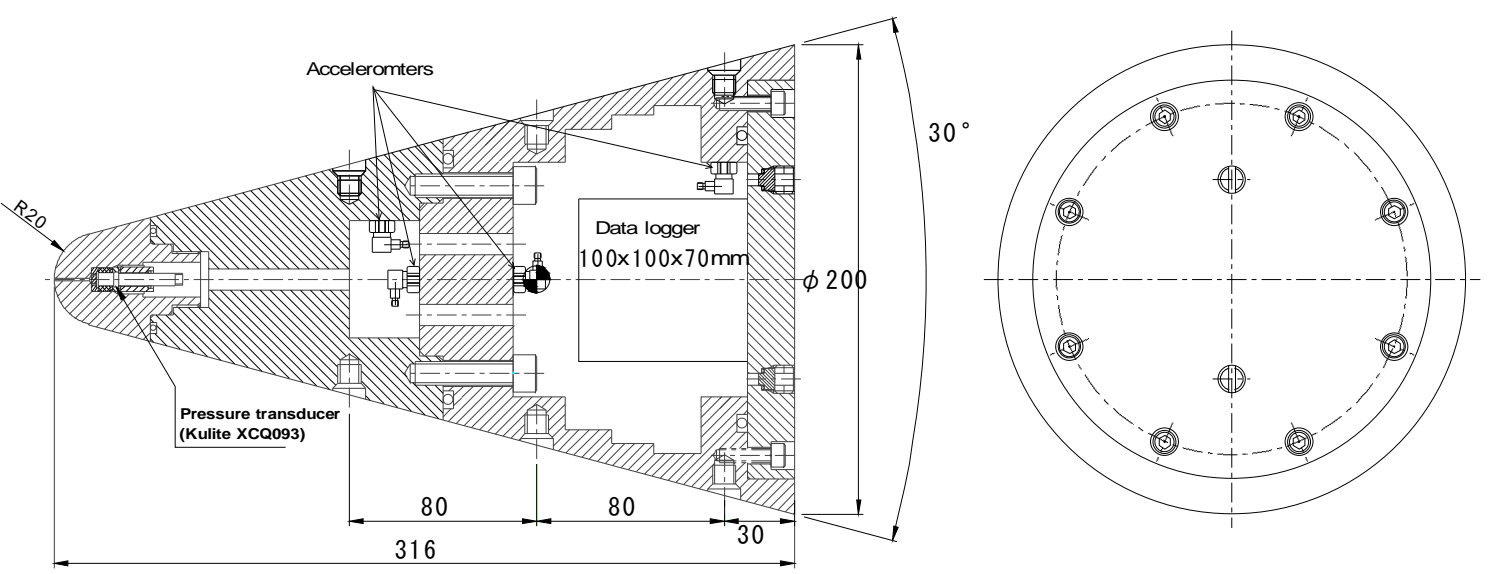

Figure.6 Schematic of the blunted-cone model. The model has a cavity inside, where the miniature data-logger can be installed. Six accelerometers were instrumented inside the model. Four of the six accelerometers are shown in the figure. 


\section{III.A Miniature data-logger}

For the present 'free-fall' aerodynamic measurement, development of the onboard miniature data-logger is key technology. To obtain the aerodynamic coefficients of test models, the multi-component force and free-stream Pitot pressure measurements are required. For instance, two acceleration measurements are required for each force and moment determination. Hence six acceleration measurements are required for six-component measurement. Free-stream Pitot pressure is required to normalize force and to obtain aerodynamic coefficients. Thus, the logger was designed to use 6 channels of piezoelectric sensors (PCB Piezotronics Inc. ICP type sensors) for accelerometer and 4 channels of piezoresistive sensors for pressure measurement.

Since the test time in HIEST is on the order of milliseconds, a sampling rate of $500 \mathrm{kHz}$ is required and a measurement accuracy of 16 bits is needed to guarantee sufficient accuracy. In addition, the logger must be small enough to mount inside the model, where space is quite tight because the space must also accommodate batteries. Table.1 shows the required specifications of the present data-logger.

Unfortunately, there is no commercial data-logger that satisfies these requirements. We therefore designed and manufactured an original data-logger. First, we investigated a PIC (peripheral interface controller) as a candidate for the data processing unit in the logger. PICs are now widely used because they are easy to apply and their prices are quite reasonable. However, PICs cannot ensure an adequate writing speed for a $500 \mathrm{kHz}$ sampling rate with 16-bit accuracy and with 10 channels to record simultaneously. So in the present data-logger we used a custom-made CLPD (complex logical programmable device) instead of a PIC. Since CLPD is hardware logic, it is not a flexible system like software logic PICs. However its operating speed is notably faster than that of PIC because of its hardware-based operation. Fig.3 shows the circuit diagram of the logger. As shown in the figure, the CPLD reads the measured signal from the $\mathrm{A} / \mathrm{D}$ converter and stores digitized data to the static memory. The logger was designed to maximize operating speed and to avoid noise, with its circuitry built on a fourlayer circuit board. The logger system includes the logger board, power regulator board and batteries. The size of the logger was set at $100 \mathrm{~mm} \times 100 \mathrm{~mm} \times 70 \mathrm{~mm}$, which is small enough to install inside of test models (shown in Fig.4)

The total measurement time of the logger is $400 \mathrm{~ms}$, and this logger has a pre-trigger system that can be adjusted arbitrarily with micro-switches on the board. In order to arm the trigger, the logger also has an IR photo switch and an LED indicator that shows the status of the logger. We made two small optical windows on the bottom plate of the blunted cone model through which we can arm the logger and see its status.

After the wind tunnel tests, data stored in the static memory of the logger were transferred to a host PC through a USB interface. Fig.5 shows the data transfer after dynamic calibration. 


\section{III.B Test model}

The test model was a blunted cone as shown in Fig.6 , which was the same cone used in the previous test campaign in $\mathrm{HIEST}^{3}$. The half-angle of the model was 15 degrees with a nose-tip radius of $20 \mathrm{~mm}$ and bottom diameter of $200 \mathrm{~mm}$. The model was made of magnetic stainless steel SUS410 instead of the usual SUS304 stainless steel. As will be described later, we used highpower electromagnets on the ceiling of the HIEST test section as a model hold-and-release system. There were concerns that the intense magnetic field produced by the electromagnets might interfere with the electrical devices in the data-logger. We thus had to make the test model from ferromagnetic materials to be expected the magnetic stainless steel SUS410 to function as a shield to prevent the field from penetrating inside the model.

The total mass of the model was $19.62 \mathrm{~kg}$ including the data-logger. Fig.7 shows the model set up in the HIEST test section. On the blunted cone model, six piezoelectric accelerometers (PCB352C65) and one piezoresistive pressure transducer (Kulite XCQ093) were instrumented. Two accelerometers for the axial direction, two for the nominal direction and two for the parallel direction were mounted inside a model to sense aerodynamic forces. Theoretically, we can conduct six-component force measurement with this instrumentation, however in this test campaign, three components were measured: the axial force, nominal force and pitching moment. The pressure transducer was mounted on the tip of the model's nose to obtain the free-stream Pitot pressure as the basis for calculating aerodynamic coefficients. Although the logger has 4 channels for the piezoresistive pressure transducers, the rest of the channels were blanked in this campaign.

The HIEST test section was usually evacuated to $2 \mathrm{~Pa}$, which was held for approximately one hour for each wind tunnel test. When designing the model, we thus aimed to retain atmospheric pressure inside the model, because the electrical devices in particular batteries in the logger (particularly batteries) were not certain to function in a vacuum. The model containing the logger was therefore designed to be a pressure chamber, sealed with O-rings, and tested as airtight at that pressure for at least 2 hours.

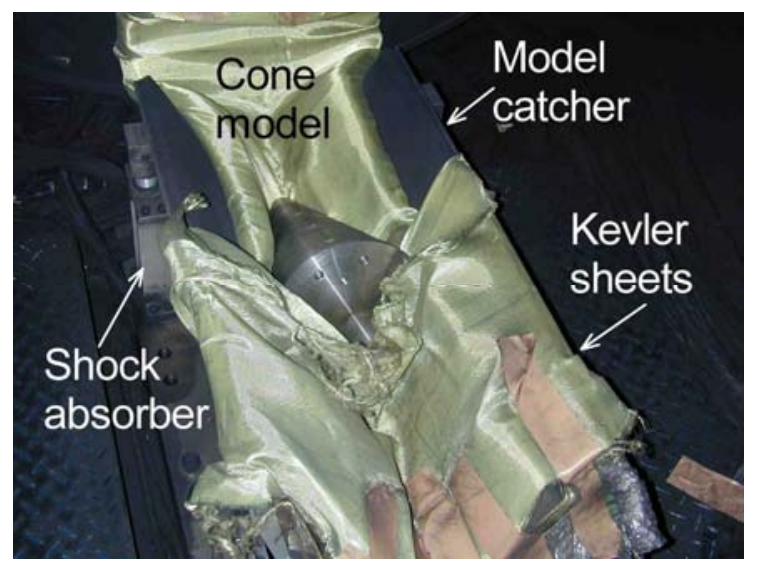

Figure.9 The test model and the model catcher immediately after the wind tunnel shot (\#1923). The blunted cone successfully soft landed on the catcher without any damage. Model and data-logger have been reused through the present test campaign.

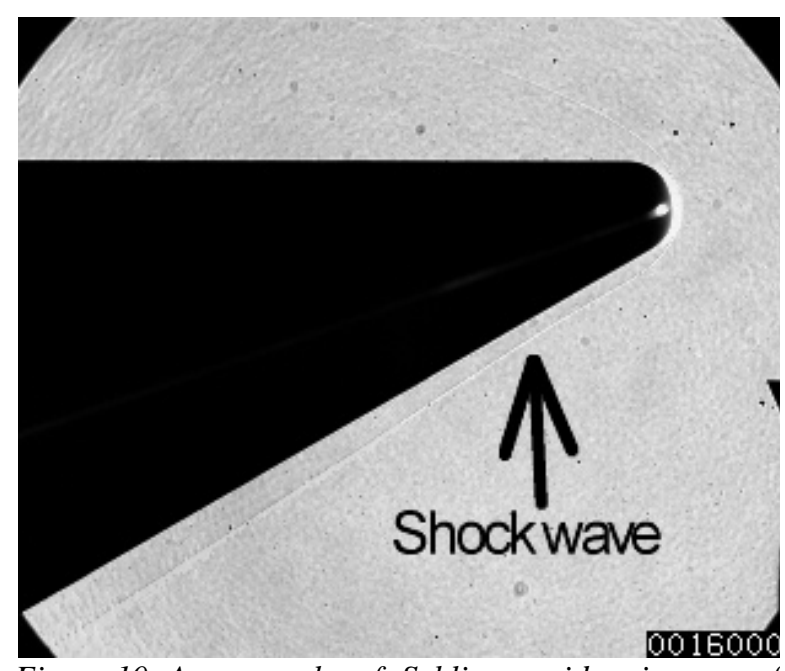

Figure.10 An example of Schlieren video images of blunted cone model, which images were used to determine model angle-of-attack during test. Test flow comes from right to left.

\section{III.C Model releaser and catcher}

\section{III.C.1 Electromagnetic model hold-and-release system}

As shown in Fig.8, the model hold-and-release system used electromagnets, which were capable of holding 60 kgf. Since the test model must be released in synchrony with the test flow arrival, the release system must respond rapidly to the trigger signal from tunnel initiation. The prototype of the release system developed in the study was located $400 \mathrm{~mm}$ above the axis of the nozzle center. This location out of free-stream flow, it is thus suitable to protect the system from the high-temperature hypersonic test flow and from the high-speed particles often produced as main-diaphragm debris. Upon test flow arrival, the model must have fallen the $400 \mathrm{~mm}$ from the release system to 
the nozzle center. The $400 \mathrm{~mm}$ free-fall requires approximately $280 \mathrm{~ms}$. Hence the trigger signal to drop the model must arrive 280 ms before the test flow does. In the present test campaign, the trigger signal was picked up from the piston launch system of the facility, which was the most up-stream section of HIEST, and this trigger signal will be obtained $400 \mathrm{~ms}$ before test flow arrival at the model in the present test setup. To adjust model release timing, a digital retarder was created. The controller, which turned the electromagnets off at precise times, included a sequencer, electrical relays, and the digital retarder.

\section{Table.2 Angle of attack of the blunted cone model} measured through Schlieren video.

$\begin{array}{cc}\text { Shot number } & \text { Angle of attack (degree) } \\ \# 1912 & 17.1 \\ \# 1913 & 16.9 \\ \# 1914 & 16.9 \\ \# 1915 & 16.8 \\ \# 1916 & 17.2 \\ \# 1917 & 16.8 \\ \# 1918 & 16.9 \\ \# 1919 & 16.1 \\ \# 1920 & 16.9\end{array}$

\section{III.C.2 Hydraulic model catcher}

The model falls $800 \mathrm{~mm}$ from the HIEST test section ceiling to the catcher located on the bottom of the HIEST test section, reaching a final speed of less than 10 $\mathrm{m} / \mathrm{s}$. In order to retrieve the model without any damages, impact should be released, hence, the catcher has a hydraulic damping system as shown in Fig.9. With these four hydraulic dampers, impact energy of $20 \mathrm{~kg} \times 10 \mathrm{~m}$ can be absorbed. In addition, shock absorbing polymer sheets were also placed on the catching surface of the system. Since the data-logger is instrumented in the model with an anti-shock mounting, the acceleration of the model and data-logger should be kept to a minimum to allow reuse of the model and data-logger.

\section{III.D Optical tracing technique to determine model angle-of-attack}

The one of the critical issues of the present measurement technique is variation of model angle-ofattack during free-fall. We measured the model attitude in a preliminary test campaign before the wind tunnel test and confirmed that the model angle of attack was held constant less than plus-minus 1 degree. However, we also made an optical measurement ${ }^{9}$ to determine the model angle of attack during the test period. In this test campaign, the angle of attack of the model was fixed at almost 17 degrees. The Fig.10 shows an example image of this optical measurement. High speed Schlieren video

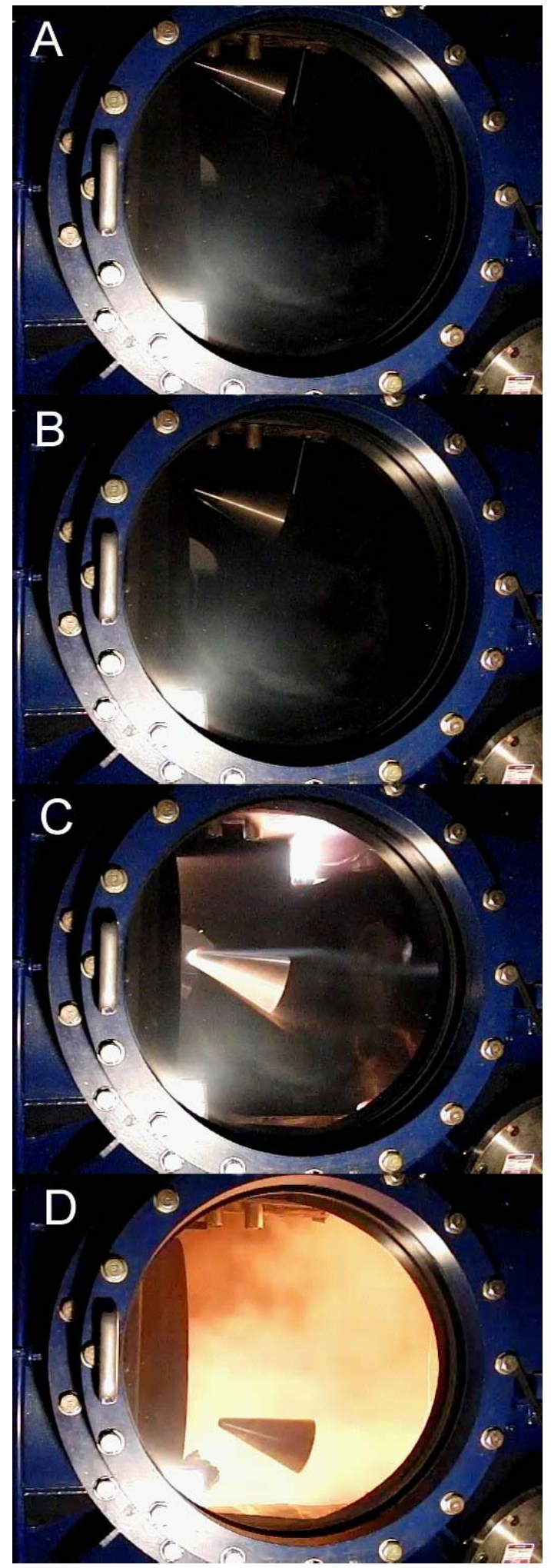

Figure.11 Sequential images of the model dropping in the HIEST test section. A. Model was clutched by the magnets. B. Model released and dropping. C. Test flow (from left to right) established around the model. D. Test finished. The model fell into the catcher. 
(SHIMAZU Hypervision) was used to obtain sequential Schlieren images around the test model. The exposure time and shutter speed of the high-speed video were 4micros, 10 micros respectively. Resolution of the angle of attack of the model was higher than 0.1 degree. Table. 2 shows the measured angle of attack during the test period. Due to variation in model positioning on the electromagnet release system, the angle of attack of each shot was slightly different. However, the variation of model angle-of-attack was at most 1.1degree.

\section{Wind tunnel test results}

Fig.11 shows sequential video images of the falling model taken with a monitoring video camera (CASIO EX-1). The model was released from the electromagnets at just the right time to be flying in the core flow during the test period. After the wind tunnel shot, the model was also successfully soft-landed in the catcher. The model and the logger experienced no damage due to mechanical shocks.
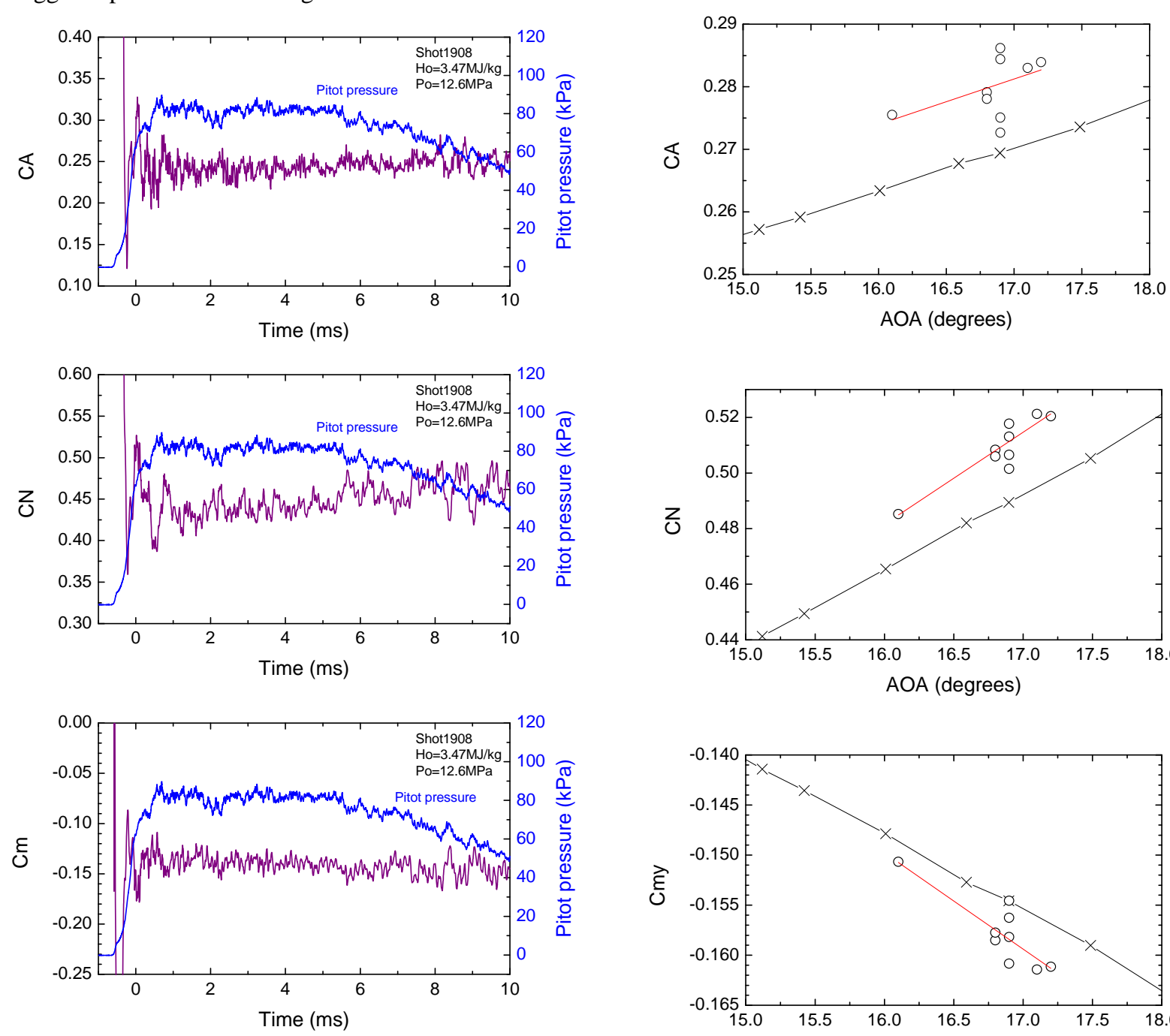

Figure.12 Time records of aerodynamic coefficients obtained in shot \#1908. Axial force coefficient $C_{A}$ (top), nominal force coefficient $\mathrm{CN}$ (middle) and pitching moment coefficient $\mathrm{Cm}$ (bottom) are shown. Pitot pressure history is also shown on each figure.
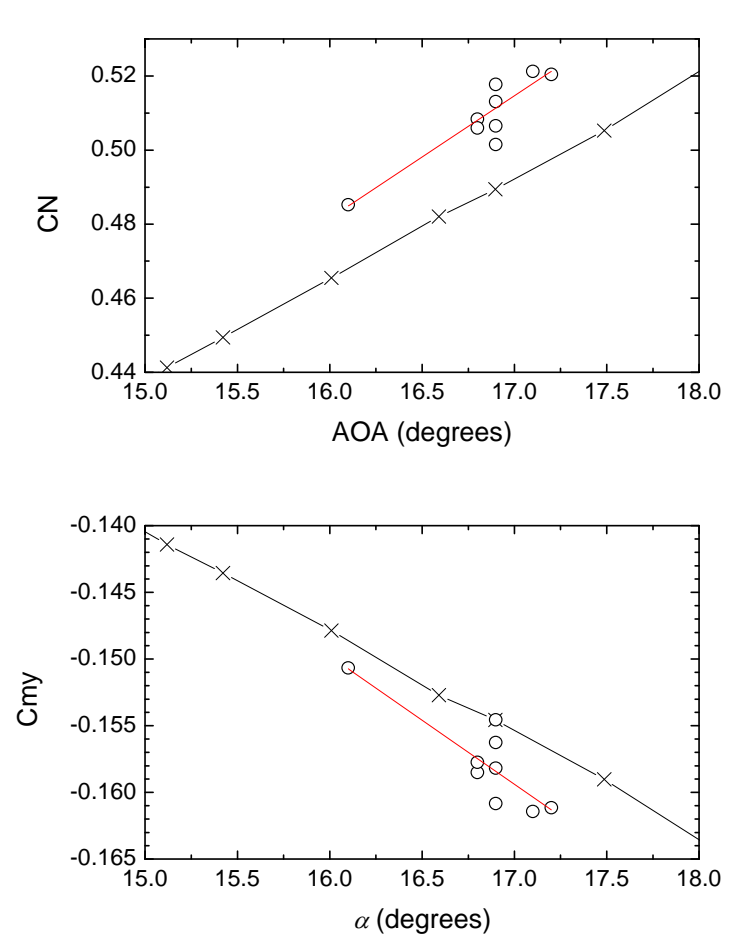

Figure.13 Aerodynamic coefficients (CA, CN and Cm) obtained in this free-fall measurement. Open circles show the data, with the $\times$ s providing a comparison with blow-down wind tunnel (JAXA-HWT2) results. 


\begin{tabular}{|c|c|c|c|c|c|c|c|c|}
\multicolumn{10}{c|}{ Table.3 Test flow conditions } \\
$\begin{array}{c}\text { Stagnation } \\
\text { temperature } \\
\mathrm{T}_{0}(\mathrm{~K})\end{array}$ & $\begin{array}{c}\text { Stagnation } \\
\text { pressure } \\
\mathrm{P}_{0}(\mathrm{MPa})\end{array}$ & $\begin{array}{c}\text { Stagnation } \\
\text { enthalpy } \\
\mathrm{H}_{0}(\mathrm{MJ} / \mathrm{kg})\end{array}$ & $\begin{array}{c}\text { Static } \\
\text { temperatur } \\
\mathrm{e}(\mathrm{K})\end{array}$ & $\begin{array}{c}\text { Static } \\
\text { pressure } \\
(\mathrm{kPa})\end{array}$ & $\begin{array}{c}\text { Free stream } \\
\text { density } \\
\left(\mathrm{kg} / \mathrm{m}^{3}\right)\end{array}$ & $\begin{array}{c}\text { Free stream } \\
\text { velocity } \\
(\mathrm{m} / \mathrm{s})\end{array}$ & $\begin{array}{c}\text { Free } \\
\text { stream } \\
\text { Mach } \\
\text { number }\end{array}$ & $\begin{array}{c}\text { Viscosity } \\
\text { Free stream } \\
\text { Unit Re }(1 / \mathrm{m})\end{array}$ \\
\hline \hline $3.04 \mathrm{E}+03$ & $1.27 \mathrm{E}+01$ & $3.75 \mathrm{E}+00$ & $2.88 \mathrm{E}+02$ & $1.12 \mathrm{E}+00$ & $1.36 \mathrm{E}-02$ & $2.58 \mathrm{E}+03$ & $7.57 \mathrm{E}+00$ & $1.79 \mathrm{E}-05$ \\
\hline \hline
\end{tabular}

\section{IV.A Test conditions}

The HIEST facility has two nozzles, one conical and one contoured. In this test campaign we used a contoured nozzle, with an exit diameter of $800 \mathrm{~mm}$, a nozzle throat of $50 \mathrm{~mm}$, and an expansion ratio of 256. Table 3 shows an example of test flow conditions (Shot \#1908), which were calculated with an axis-symmetrical in-house nozzle flow code $^{10}$. In the present test campaign, shots were fixed at a stagnation enthalpy $\mathrm{H}_{0}$ of approximately $\mathrm{H}_{0}=3 \mathrm{MJ} / \mathrm{kg}$ and a stagnation pressure of $\mathrm{P}_{0}=13 \mathrm{MPa}$. Since a longer test time will be available at lower stagnation enthalpies in freepiston shock tunnels, a test time of 6 ms was estimated under the conditions of this campaign.

\section{IV.B Force measurement histories}

Figs. 12a to 12c show the time history of the axial force coefficient $\mathrm{C}_{\mathrm{A}}$, nominal force coefficient $\mathrm{C}_{\mathrm{N}}$ and pitching moment coefficient $\mathrm{C}_{\mathrm{m}}$. All the coefficients were obtained from the forces and moment divided by the product of the dynamic pressure $\mathrm{q}$ and by the cross section of the blunted cone model. Stagnation enthalpy affects the specific heat of the flow, and the dynamic pressure q can thus be calculated as $\mathrm{q}=1.064 \mathrm{Pt}$ when $\mathrm{H}_{0}$ is approximately $4 \mathrm{MJ} / \mathrm{kg}$. As shown in the figures, aerodynamic coefficients seemed quasi-steady from $1 \mathrm{~ms}$ to $5 \mathrm{~ms}$ on the time scale (x-axis) in the figure. Hence aerodynamic coefficients were averaged in the time period (4 ms duration).

\section{IV.C Measurement accuracy}

Fig.13 shows the relation between aerodynamic coefficients and AOA (angle of attack) obtained in the test campaign. All measurements are shown as open circles. The measurement precision (2-sigma) of this free-fall measurement is summarized in Table.4. Although detailed analysis of the measurements is required, the precision was excellent in this preliminary analysis.

In the figure, results measured in the blow-down hypersonic wind tunnel (JAXA-HWT2) results were also plotted to estimate accuracy of the measurement results. Since post-calibration has not yet conducted, discussion of accuracy would be premature. A preliminary comparison shows a difference of less than $4.5 \%$ from the blow-down wind tunnel results.

\begin{tabular}{ccc} 
Table.4 Precision and accuracy of the present measurement \\
\hline & 2 -sigma & Difference from HWT2 \\
CA & $\pm 1.04 \%$ & $4.1 \%$ \\
CN & $\pm 0.96 \%$ & $4.5 \%$ \\
My & $\pm 0.45 \%$ & $-2.5 \%$
\end{tabular}

\section{Summary}

A miniature data-logger was developed, which was designed to be mounted onboard on wind tunnel test models in the free-piston shock tunnel HIEST. For the demonstration of the whole measurement system, a three-component aerodynamic force measurement test was conducted in HIEST with a data-logger onboard blunted cone. The axial force, nominal force and pitching moment coefficient, and free-stream Pitot pressure were successfully recorded with the logger under the flow condition equivalent to the flight Mach number 8 . These measurements clearly demonstrated that the present technique has sufficient performance to measure aerodynamic coefficients during the 
short test period available for impulsive facilities like HIEST. Moreover, the logger successfully showed the potential to eliminate any sting interference with model base flow.

\section{REFERENCES}

${ }^{1}$ Itoh, K., Ueda, S., Tanno, H., Komuro, T. and Sato, K., "Hypersonic Aerothermodynamic and Scramjet Research Using High Enthalpy Shock Tunnel,” Shock Waves, Vol.12, 93-98, 2002.

${ }^{2}$ Tanno, H. et al., ”Unsteady force measurement technique in shock tubes”, Rev.Sci.Inst. Vol.75, No.2, 2004.

${ }^{3}$ Tanno, H., et al., "Miniature data-logger for aerodynamic force measurement in impulsive facility", AIAA Paper No.20104204, 2010

${ }^{4}$ Bernstein, L.,’”Force measurement in short-duration hypersonic facilities.”, AGARD-AG-214, edited by R.C. Pankhurst (Technical Editing and Reproduction, London,1975.

${ }^{5}$ Duryea, G. R. \& Sheeran W. J. “Accelerometer force balance techniques”, ICIASF'69 record, IEEE publication 69 C 19AES,1969.

${ }^{6}$ Reddy, N. M.,’Aerodynamic force measurements in the IISc hypersonic shock tunnel”, Proc.14 ${ }^{\text {th }}$ Int. Symp. on Shock Waves and Shock Tubes, pp.358-362.,1983

${ }^{7}$ Naumann, K.W., Ende, H., Mathieu, G., \& George, A. ”Millisecond Aerodynamic force measurement with side-jet model in the ISL shock tunnel.”, AIAA J., Vol.31., No.6. 1993

${ }^{8}$ Tanno, H., et al., "Aerodynamic characteristics of generic models under real-gas condition in the free piston shock tunnel HIEST”, AIAA Paper No.2008-2567, 2008

${ }^{9}$ Stuart J.L., and S. Karl "An improved visualization-based force-measurement technique for short duration hypersonic facilities”, Experiments in Fluids, Vol.48, 6, 2010.

${ }^{10}$ Takahashi M., et al., "Influence of Thermal Non-Equilibrium on Nozzle Flow Condition of High Enthalpy Shock Tunnel HIEST_”, AIAA Paper No.2009-7267, 2009. 